Results: Of 385 patients with RA were included in the analysis. Their demographics are shown in the Table.1 Patients scoring 3 or more on the PHQ had more severe RA (higher DAS/HAQ), but there was no significant difference in age, sex or disease duration. $124(32 \%)$ reported no work disability, with the overall mean score 3.0. Patients screening positive for depression had a significantly lower work ability even after adjusting for available confounders.

Conclusions: There is a significant correlation between depression in RA and work ability, which persists even after accounting for disease severity. The magnitude of association observed was even greater than that seen between physical function and work. Although unmeasured confounding remains likely, these data confirm the link between depression and work in RA. It is likely that the relationship is bidirectional, between depression and work in RA. Beyond the importance of addressing work ability in RA, the results highlight the need for screening and targeting depression as part of routine clinical care beside the holistic approach of mangement.

Disclosure of Interest: None declared

DOI: 10.1136/annrheumdis-2017-eular.6513

\section{SAT0099 POLYPHARMACY IS ASSOCIATED WITH AN INCREASED RISK OF ADVERSE OUTCOMES IN PATIENTS WITH RHEUMATOID ARTHRITIS}

A.D. Amarilla Vallejo ${ }^{1}$, A. Rutherford ${ }^{1}$, M. Filkova $^{2}$, M. Molokhia $^{3}$,

E. Nikiphorou ${ }^{1}$, S. Norton ${ }^{1}, \mathrm{~K}$. Hyrich ${ }^{4}, \mathrm{~J}$. Galloway ${ }^{1} .{ }^{1}$ Academic Department of Rheumatology, King's College London, London, United Kingdom; ${ }^{2}$ Institute of

Rheumatology and Department of Rheumatology, 1st Faculty of Medicine, Charles University, Prague, Czech Republic: ${ }^{3}$ Primary Care and Public Health Sciences, King's College London, London; ${ }^{4}$ Arthritis Research UK. Epidemiology Unit, University of Manchester, Manchester, United Kingdom

Background: In the general population, polypharmacy (PP) is associated with increased risk of adverse events. The relationship between adverse outcomes and PP in Rheumatoid Arthritis (RA) has not been studied in depth. The mantra of treatment in RA encourages PP through combination Disease Modifying Anti-Rheumatic Drugs (DMARD).

Objectives: To study the relationship between PP and serious adverse events in RA, including the influence of DMARDs within the PP count.

Methods: Data from the British Society for Rheumatology Biologics Register were analysed. PP was defined as number of drugs co-prescribed at baseline, with two models: (1) including DMARDs (2) excluding DMARDs from the medication count. PP was stratified by $0-5,6-9$ and $>10$. Patients were studied from initiation of 1st biologic until 1st serious adverse event (SAE), 3 years of follow up, or last available visit, whichever came first. A Cox-proportional hazard model was used, with adjustment for a priori selected cofounders.

Results: This study included 15,004 patients commencing biologics. The demographics are shown in table 1. Excluding DMARDs from the PP cohort, $7,115(47 \%)$ of the patients were taking up to 5 drugs; 6,010 (40\%) were taking 6 to 9 drugs; $1,870(12 \%)$ were taking 10 or more medications. Higher levels of PP associated with older age, more severe disease, and longer disease duration. PP predictably associated with comorbidities; the relationship was not linear: comorbidity count appeared to show a ceiling effect. The overall incidence of SAEs was $25.5 / 100$ person years $(95 \% \mathrm{Cl} 24.7-26.3)$. The rate of SAEs increased across the PP counts (See Table 1). The relationship remained significant after adjusting for comorbidities. Including DMARDs within the PP count attenuated the association.

Conclusions: PP is common in patients with RA and is associated with adverse outcomes especially when patients are on $>10$ drugs. Including or excluding DMARDs from the PP model had negligible impact on findings. The relationship between PP and comorbidity is worthy of further research, as PP represents a potentially simple but valuable predictor of adverse outcomes, and a suitable surrogate for comorbidity in epidemiological analyses.

Disclosure of Interest: None declared

DOI: 10.1136/annrheumdis-2017-eular.2262

Abstract SAT0099 - Table 1

\section{SAT0100 ACPA AND ABDOMINAL ADIPOSITY ARE INDEPENDENT PREDICTORS OF INCREMENTS IN BASAL INSULIN IN PATIENTS WITH RA}

E. Gomez-Bañuelos ${ }^{1}$, K. Arrona-Rios ${ }^{2}$, S. Duran-Barragan ${ }^{3}$,

L. Gonzalez-Rosas ${ }^{2}$, J. Aquilar-Arreola ${ }^{2}$, F.D.J. Perez-Vazquez ${ }^{1}$,

G.-I. Diaz-Rubio ${ }^{1}$, E. Chavarria-Avila ${ }^{1}$, F. Corona-Meraz ${ }^{1}$, A. Saldaña-Millan ${ }^{1}$, R.-E. Navarro-Hernandez ${ }^{1}$, M. Vázquez-Del Mercado ${ }^{1,2} .{ }^{1}$ Instituto de Invesgitación en Reumatología y del Sistema Musculoesquelético, Universidad de Guadalajara; ${ }^{2}$ Servicio de Reumatología, División de Medicina interna, Pnpc 004086, CONACYT; ${ }^{3}$ Instituto de Invesgitación en Reumatología y del Sistema Musculoesquelético, Hospital Civil de Guadalajara, "Juan I. Menchaca", Guadalajara, Mexico

Background: Insulin resistance (IR) is a comorbidity found in about $40 \%$ of RA patients. Currently, there is little information regarding the role of antibodies against citrullinated proteins and IR development in RA. Patients positive for ACPA and/or RF may be at higher risk of IR since these group of patients has a higher expression pro-inflammatory citokines like TNFa and IL-6, both implicated in the pathogenesis of IR.

Objectives: To analyze the contribution of autoantibodies positivity (ACPA and/or $\mathrm{RF}$ ) and their impact in the development of IR in patients with RA.

Methods: We retrospectively analyzed patients classified with RA per ACR 1987 and ACR/EULAR 2010 criteria with at least one year of follow-up in a cohort of RA patients without comorbidities from Hospital Civil "Juan I. Menchaca". DAS-28, basal insulin, HOMA-IR and anthropometric parameters: Body weight, body mass index (BMI), Sum 4 skinfold thicknesses (S4T), Waist to hip ratio (WHR), waist circumference (WC) and total fat mass (FM); were determined at current and baseline. Mean differences between the two time points were calculated. A multiple regression model was constructed considering mean insulin change as dependent variable.

Results: We studied 57 RA patients, $44 \%$ (25) with IR and $56 \%$ (32) without IR. Of these, 21\% (12) developed IR during follow-up. BMI, FM and ST4 were higher at baseline in patients with current IR at baseline. Ptients who developed IR during follow-up had a mean increase of DAS-28 of $1.27(\mathrm{P}<0.005$ vs. patients who improved or never developed IR). Patients positive for ACPA had a greater increase in IR during follow-up. Multivariate analysis revealed that ACPA, increments in WHR and ST4 were independent predictors of basal insulin increases during follow-up.

Conclusions: ACPA and abdominal adiposity (WHR) are independent predictors of IR development in RA

Disclosure of Interest: None declared

DOI: 10.1136/annrheumdis-2017-eular.6862

\section{SAT0101 POSSIBILITY OF BACTERIAL INFECTION PROPHYLAXIS OF TRIMETHOPRIM-SULFAMETHOXAZOLE IN ELDERLY PATIENTS WITH RHEUMATOID ARTHRITIS UNDERGOING TREATMENT WITH BIOLOGICS: A SINGLE-CENTER, RETROSPECTIVE, CASE-CONTROL STUDY}

E. Kikuchi, N. Aoki, T. Yoshioka, T. Okai. Center for Rheumatology and Joint Surgery, Kawakita General Hospital, Tokyo, Japan

Background: Trimethoprim-sulfamethoxazole (TMP-SMX) is widely used for the prophylaxis of Pneumocystis jiroveci pneumonia (PCP) in immunocompromised patients, but data about the prophylactic effect of TMP-SMX against bacterial infections are insufficient.

Objectives: To analyze the prophylactic effect of TMP-SMX against severe bacterial infections in elderly patients with rheumatoid arthritis undergoing treatment with biologics.

Methods: Data were retrospectively collected from the medical records of patients with rheumatoid arthritis at our center. We divided the elderly patients (65 years or above) who took biologic agents into two groups. The first group (TMP-SMX+) comprised patients who previously or concurrently started TMP-SMX with biologic

\begin{tabular}{|c|c|c|c|c|}
\hline & \multirow[t]{2}{*}{ All Patients } & \multirow{2}{*}{\multicolumn{2}{|c|}{$\begin{array}{c}0-5 \text { drugs } \\
P P \text { count excluding DMARDs }\end{array}$}} & \multirow{3}{*}{$\begin{array}{c}>10 \text { drugs } \\
n=1,870\end{array}$} \\
\hline & & & & \\
\hline & $\mathrm{N}=15,004$ & $\mathrm{n}=7,115$ & $n=6,019$ & \\
\hline \multicolumn{5}{|l|}{ Baseline characteristics } \\
\hline Mean Age in years & 56.3 & 54.0 & 57.6 & 61.0 \\
\hline Mean DAS 28 (SD) & $4.30(1.76)$ & $4.17(1.79)$ & $4.51(1.67)$ & $4.88(1.67)$ \\
\hline Mean HAQ (SD) & $1.93(0.64)$ & $1.85(0.65)$ & $2.10(0.56)$ & $2.15(0.58)$ \\
\hline Mean Disease Duration (SD) in years & $12.59(9.72)$ & $11.96(9.32)$ & $13.79(10.26)$ & $14.67(10.96)$ \\
\hline Comorbidity (SD) & $1.87(0.80)$ & $1.65(0.74)$ & $2.29(0.73)$ & $2.57(0.68)$ \\
\hline \multicolumn{5}{|l|}{ Analysis of Serious Adverse Events } \\
\hline Exposure time (person-years) & 14,200 & 9,690 & 3,706 & 804 \\
\hline Event count (single failure model) & 3261 & 2002 & 1251 & 368 \\
\hline Incidence rate $(95 \% \mathrm{Cl})$ & $25.5(24.7-26.3)$ & $20.6(19.7-21.5)$ & $33.7(31.9-35.6)$ & $45.7(41.3-50.7)$ \\
\hline \multicolumn{5}{|l|}{ Including DMARDs in PP model } \\
\hline Unadjusted HR (95\% Cl) & - & Ref & $1.20(1.11-1.29)$ & $1.82(1.66-1.99)$ \\
\hline Adjusted HR $(95 \% \mathrm{Cl})$ & - & Ref & $1.05(0.97-1.13)$ & $1.39(1.26-1.54)$ \\
\hline \multicolumn{5}{|l|}{ Excluding DMARDs in PP model } \\
\hline Unadjusted HR $(95 \% \mathrm{Cl})$ & - & Ref & $1.63(1.52-1.75)$ & $2.21(1.98-2.47)$ \\
\hline Adjusted HR (95\% Cl) & - & Ref & $1.18(1.09-1.28)$ & $1.35(1.19-1.53)$ \\
\hline
\end{tabular}

Adjusted for age, sex, DAS, HAQ, disease duration and comorbidities. 